\title{
Mitteilungen der DGIIN
}

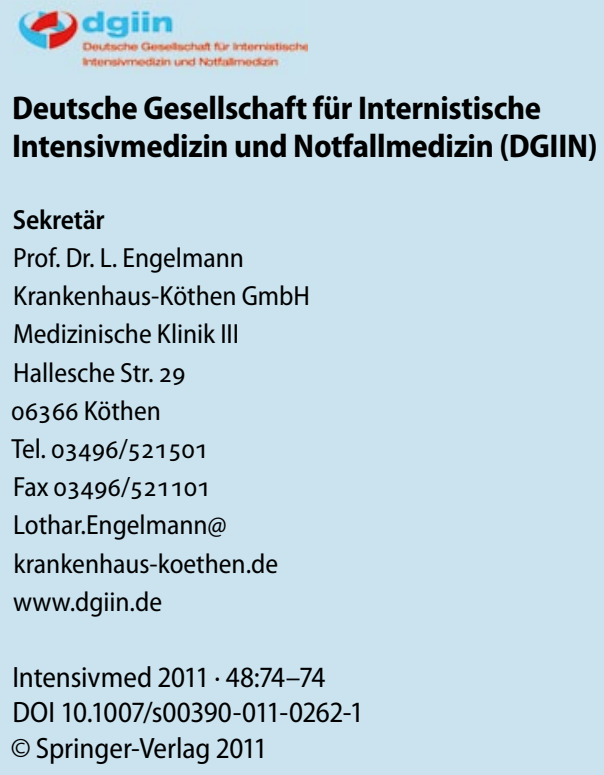

\section{Forschungspreis- ausschreibungen 2011}

Die Deutsche Gesellschaft für Internistische Intensivmedizin und Notfallmedizin schreibt

-1. den Forschungspreis „Intensivmedizin“ (dotiert mit 5.00o Euro)

und

-2. den Forschungspreis „Notfallmedizin“ (dotiert mit 2500 Euro)

für das Jahr 2011 aus.

Die Forschungspreise dienen der Auszeichnung besonderer wissenschaftlicher experimenteller und klinischer Arbeiten auf dem Gebiet der internistischen und allgemeinen Intensivmedizin bzw. der Notfallmedizin von Mitgliedern der Deutschen Gesellschaft für Internistische Intensivmedizin und Notfallmedizin.

Die weiteren Kriterien sind in den Vergaberichtlinien (siehe www. dgiin.de) zu ersehen.

Die Bewerber sind gebeten, die Preisarbeit entsprechend den Vergaberichtlinien bis zum 15. März 2011 bei der Geschäftsstelle der DGIIN einzureichen (Geschäftsstelle DGIIN e.V., Seumestraße 8, 10245 Berlin).
Die Preisträger werden über die Zuerkennung der Forschungspreise bis spätestens 31. Mai 2011 informiert.

Die Verleihung erfolgt anlässlich der Jahrestagung der Deutschen Gesellschaft für Internistische Intensivmedizin und Notfallmedizin und der Österreichischen Gesellschaft für Internistische und Allgemeine Intensivmedizin vom 15.-18. Juni 2011 in Wien. Eine Kostenübernahme für die Teilnahme am Kongress durch die DGIIN kann für die Preisträger nicht erfolgen.

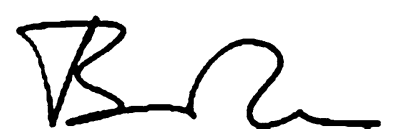

Prof. Dr. M. Buerke Präsident der DGIIN

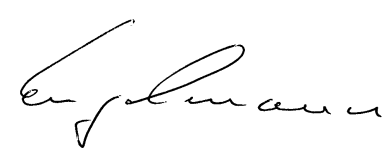

Prof. Dr. L. Engelmann Generalsekretär der DGIIN 